九州大学学術情報リポジトリ

Kyushu University Institutional Repository

\title{
Numerical Studies of Flow around a Wind Turbine Equipped with a Flanged-Diffuser Shroud using an Actuator-Disk Model
}

Ohya, Yuj i

Research Institute for Applied Mechanics, Kyushu University

Uchida, Takanori

Research Institute for Applied Mechanics, Kyushu University

Karasudani, Takashi

Research Institute for Applied Mechanics, Kyushu University

Hasegawa, Masaru

Department of Aeronautics and Astronautics, Kyushu University

他

http://hdl. hand le. net/2324/26426

出版情報: Wind Engineering. 36 (4)，pp.455-472，2012-08. Multi Science Publishing バージョン：

権利関係 : 


\title{
Numerical Studies of Flow around a Wind Turbine Equipped with a Flanged-Diffuser Shroud using an Actuator-Disk Model
}

\author{
Yuji Ohya*', Takanori Uchida*', Takashi Karasudani*', \\ Masaru Hasegawa*2 and Hiroshi Kume*2 \\ *lKyushu University, Research Institute for Applied Mechanics, Kasuga, 81 6-8580 Japan \\ *2 Kyushu University, Dept. of Aeronautics and Astronautics, Kasuga, 816-8580 Japan
}

\begin{abstract}
Unsteady 3-D direct numerical simulations based on the finite-difference method (FDM) were performed for flow fields around a wind turbine equipped with a flanged-diffuser shroud. Generally, it is difficult to numerically simulate the flow around rotating bodies such as the blades of wind turbines because of the unsteady flow generated by moving bodies with complex geometry. Therefore, we have devised an actuator-disk model for a wind turbine for simulating the drag and rotational forces exerted on the fluid by the wind turbine. By incorporating the body forces derived from the actuator-disk model into the external terms in the Navier-Stokes equations, the unsteady flow around a wind turbine can be simulated. The results of numerical simulations were compared with the results from wind tunnel experiments and showed good agreement for the velocity and pressure fields.
\end{abstract}

Key Words: Wind Energy, Wind Turbine, Flanged Diffuser, Wind Tunnel Experiment, CFD

\section{INTRODUCTION}

Being clean and reusable, wind power energy has grown in use dramatically in the midst of global warming and fossil fuel depletion and will likely assume a significant role in the field of new energy. In the Wind Lens research group of Kyushu University, Japan, wind turbines with flanged-diffuser shrouds have been developed(1)(2). These turbines are able to generate a significant amount of energy even in areas with low wind speed and larger amounts of energy than would otherwise be produced in areas with wind speeds considered appropriate for conventional wind power generation. Known also as "Wind Lens turbines," these turbines were developed based on the principle that wind power generation is proportional to the cube of the wind speed. Specifically, a wind collecting structure, that is, a diffuser shroud with a flange at the wind outlet, was invented for installation around a wind turbine so that the speed of the wind approaching the wind turbine can be raised and a significant increase in power output can be achieved. The flow field around the Wind Lens turbine is characterized as a typical bluff-body flow field with a complex structure, which includes turbulence in the wakes of the wind turbine blades, separation and reattachment of the boundary layer along the internal walls of the diffuser shroud, shedding of large vortices from the flange in the external flow around the diffuser shroud, and mixing of the internal and external flows at the outlet of the diffuser shroud 


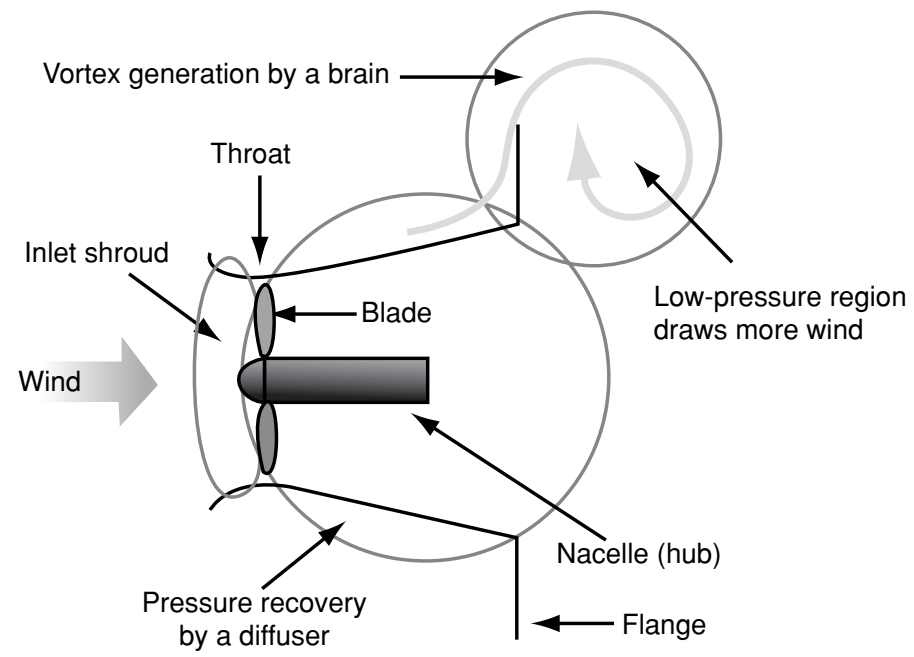

Figure 1: A wind turbine equipped with a flanged-diffuser shroud.

(Fig. 1). A better understanding of the flow around the Wind Lens turbine will lead to improved energy output performance of the turbine, and is at the same time of interest from the viewpoint of fluid dynamics.

Regarding the flow around the Wind Lens turbine, Abe et al.(3)(4) conducted numerical studies with a turbulence model in order to compare the time-averaged flow field and the value of the power output coefficient from the simulation to those from a wind tunnel experiment. In their studies, the turbine was modeled simply as a resistance to the flow, and the disk-loading method was adopted. Furthermore, for airflows around a conventional wind turbine without a diffuser shroud, Sorensen et al. ${ }^{(5)(6)}$ conducted numerical simulations using the actuator-disk model.

In the present study, a numerical simulation of the airflow around a Wind Lens turbine is performed using the actuator-disk model, which is able to simulate the spiral flow as well as the drag induced by the turbine on the flow. The actuator-disk model also allows a more realistic representation of the wind turbine than the disk-loading method. In the course of the analysis, the unsteady flow field around the Wind Lens turbine is simulated using direct numerical simulation (DNS) so that the airflow around the turbine can be examined in detail and the simulation results can be validated against the results from a wind tunnel experiment.

\section{COMPUTATIONAL AND WIND TUNNEL EXPERIMENTAL METHODS}

\section{I. Computational method}

Numerical simulations of the flow around a Wind Lens turbine were conducted using a threedimensional DNS which was based on the finite difference method. The governing equations consisted of the continuity and Navier-Stokes equations. Table 1 summarizes the details of the approach and other information relevant for the simulation. Figs. 2 and 3 illustrate the entire computational domain with boundary conditions and the computational grids around the Wind Lens turbine, respectively. Fig. 4 shows the two variations of the Wind Lens turbine, a long-style and a compact-style, which were considered for the simulations.

In the present simulations, the Reynolds number, $R e$, which is based on the inner diameter of the throat of the diffuser shroud, $D$, (see Fig. 7) is 10,000. This value is an order of magnitude smaller than the value of the Reynolds number for the wind tunnel experiment. However, as described in later sections, the profiles of the wind velocity and static pressure inside the 
Table I: Simulation schemes and computational settings

\begin{tabular}{ll}
\hline Coordinate system & 3-D body-fitted coordinate system \\
Variable arrangement & Collocated \\
Computational grid & H-O type \\
Scheme & Finite difference method (DNS) \\
Coupling algorithm & F-S method \\
Time advancement method & Euler explicit method \\
Discretization of advective terms & $3^{\text {rd }}$-order upwind scheme \\
Iteration formula for Poisson equation & Successive over-relaxation method \\
Reynolds number & 10,000 based on $D$ \\
\hline
\end{tabular}

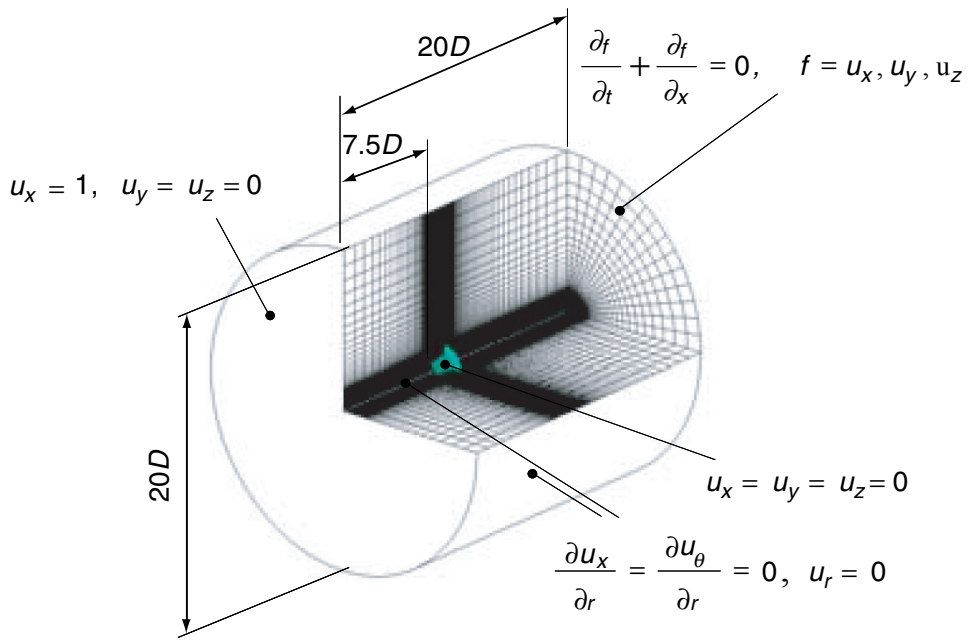

Figure 2: Computational grid of the whole domain and boundary conditions.

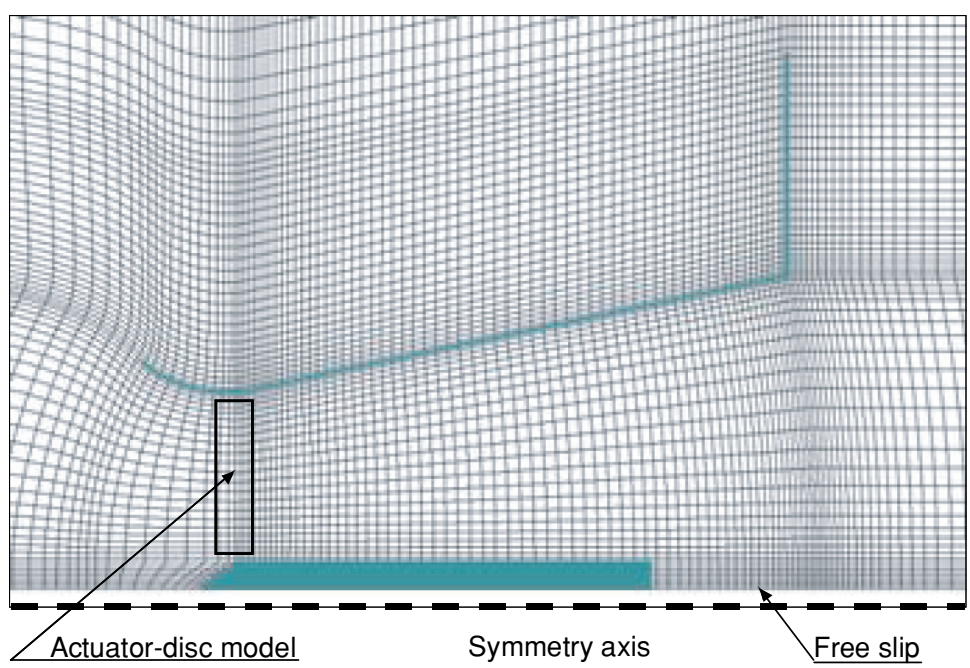

Figure 3: Computational grid around the flanged-diffuser shroud.

diffuser shroud agree well between the wind tunnel experiment and the simulations. From these results, the authors concluded that no essential differences exist between the flow from the simulations and that from the wind tunnel experiment in the range from $R e=10^{4}$ to $R e=10^{5}$ although the Reynolds number differs between these flows. 

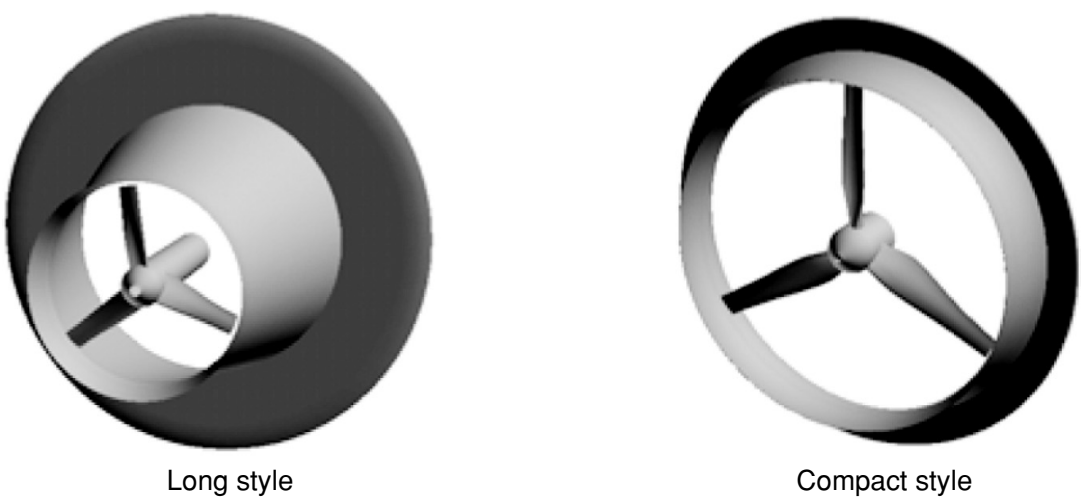

Figure 4: Wind turbines equipped with two variations of a flanged -diffuser shroud.

\subsection{Wind tunnel experimental method}

The large-scale boundary-layer wind tunnel of the Research Institute for Applied Mechanics was used for the present wind tunnel experiments. The measurement section of the wind tunnel is $3.6 \mathrm{~m}$ (width) $\times 2 \mathrm{~m}$ (height) $\times 15 \mathrm{~m}$ (length), and a maximum wind speed of $30 \mathrm{~ms}^{-1}$ can be produced. Because relatively large wind turbine models were used for the experiment, the ceiling and side panels in the central measurement section were removed, creating a semiopen measurement section. This arrangement was made in order to address the blockage effect in the measurement section.

Two variations of the diffuser shroud with configurations identical to those considered for the numerical simulations were created with fiber-reinforced plastic (FRP). For adjusting the size of the flange $h$, (see Fig. 7) a ring-like structure was fabricated using Woodlac ${ }^{\circledR}$ Panel (polystyrene foam), and the structure was added to the diffuser shroud outlet. In order to suspend the diffuser shroud model in the wind tunnel, spokes were added radially from a brass shaft extending from the $\mathrm{AC}$ servo motor, which was used to control the rotation of the blades (see Fig. 5 for the experimental arrangement).

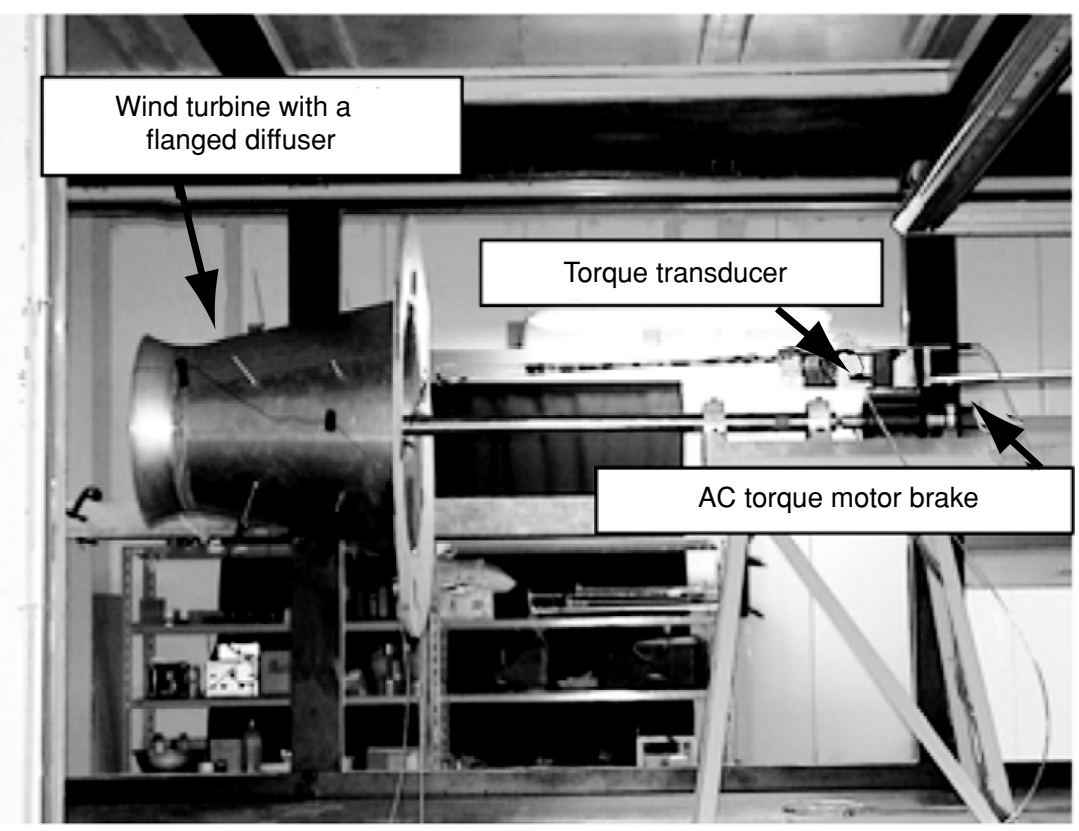

Figure 5: Experimental arrangement for output performance tests. 
Based on a simple theory of the Wind Lens wind turbine ${ }^{(7)}$, two types of turbine blades, NACA and MEL blades ${ }^{(8)}$, were prepared for use in the experiment. Fig. 6 shows an overview of the two kinds of blades. The cross-sections of the NACA blades consisted of the aerofoil shapes NACA63-218, NACA63-215, and NACA63-212 in sequence from blade root to blade tip. Similarly, the cross-sections of the MEL blades consisted of the aerofoil shapes MEL20M01, MEL18M31, and MEL12M84 in sequence from blade root to blade tip.

The distributions of wind velocity, $u_{x}$, and static pressure, $p$, within the diffuser shroud models were measured using a hot-wire anemometer (I-type probe) and a static pressure tube for airflow pressure measurements both of which were mounted on a traverse. The static pressure coefficient is defined as $C_{p s}=\left(p-p_{0}\right) /\left(0.5 \rho U_{0}^{2}\right)$, where $U_{0}$ is the wind velocity far upstream of the measurement location, $\rho$ is the air density, $p$ is the static pressure, and $p_{0}$ is the static pressure corresponding to $U_{0}$. The tip speed ratio is defined as, $\lambda=\left(R w / U_{0}\right)$, where $R$ is the rotor radius and $\omega$ is the angular velocity. Fig. 7 shows the parameters relevant for the

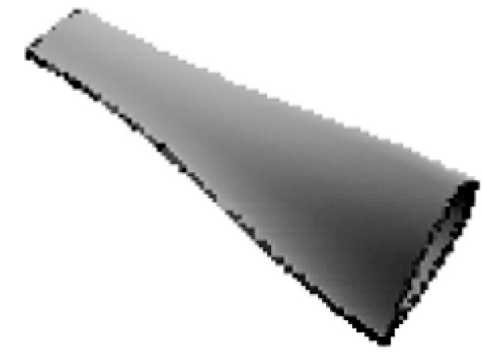

NACA blade

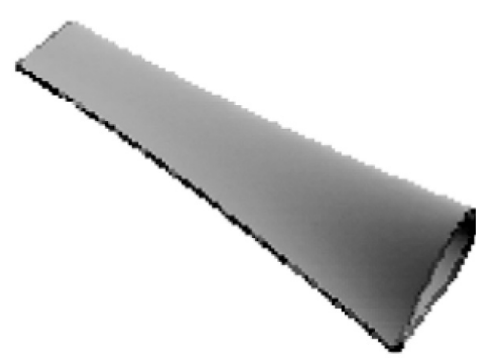

MEL blade

Figure 6: 0verview of two types of wind turbine blades.

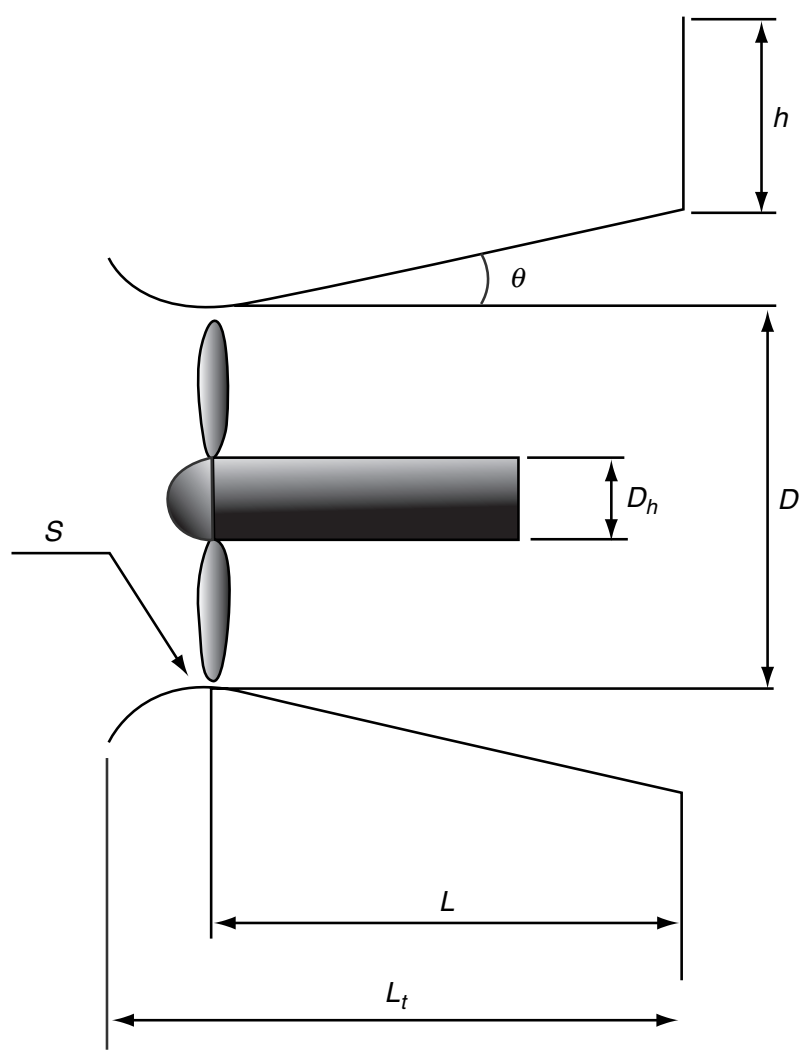

Figure 7: Parameters for a wind turbine with a flanged -diffuser shroud. 
Table 2: Detailed information of wind turbines with flanged-diffuser shrouds and experimental conditions

\begin{tabular}{lcc}
\hline Experimental model & Long style & Compact style \\
\hline Type of the blade & NACA blade & MEL blade \\
Diameter of throat $D$ & $600 \mathrm{~mm}$ & $1020 \mathrm{~mm}$ \\
Diameter of hub $D_{h}$ & $0.22 \mathrm{D}$ & $0.13 \mathrm{D}$ \\
Diffuser length $L$ & $1.25 \mathrm{D}$ & $0.137 \mathrm{D}$ \\
Inlet length + diffuser length $L_{t}$ & $1.5 \mathrm{D}$ & $0.225 \mathrm{D}$ \\
Height of flange $h$ & $0.5 \mathrm{D}$ & $0.1 \mathrm{D}$ \\
Tip clearance $s$ & $10 \mathrm{~mm}$ & $10 \mathrm{~mm}$ \\
Semi-open angle $\theta$ & $12^{\circ}$ & $12^{\circ}$ \\
Reynolds number, $R e$, based on $D$ & $2.2 \times 10^{5}$ & $5.5 \times 10^{5}$ \\
Experimental velocity $U_{0}$ & $6 \mathrm{~m} / \mathrm{s}$ & $8 \mathrm{~m} / \mathrm{s}$ \\
\hline
\end{tabular}

configuration of the Wind Lens turbine. Table 2 summarizes the characteristics length scales and configuration data for the Wind Lens turbines used in the experiments and also the values of the Reynolds number and wind velocity from the experiments.

\subsection{Actuator-disk modeling of wind turbine blades}

In this section, the external forces exerted by the rotating wind turbine blades on the fluid are formulated based on the blade element theory and the actuator disk approach. Fig. 8 illustrates the inflow wind impinging on a cross-section of the wind turbine blade at an arbitrary position along the span of the blade and the aerodynamic forces which emerge as a result of the interaction of the wind and the blade. In the figure, the direction of uniform flow at an infinite distance and the direction of blade rotation are denoted as $+x$ and $+\theta$, respectively. As for $V$ and $\alpha$, the following equations hold:

$$
\begin{aligned}
& V=\sqrt{u_{x 1}^{2}+\left(r \omega-u_{\theta 1}\right)^{2}} \\
& \alpha=\tan ^{-1}\left(\frac{u_{x 1}}{r \omega-u_{\theta 1}}\right)-\gamma
\end{aligned}
$$

Given the blade configuration, the pitch angle, $\gamma$, at an arbitrary position along the span measured from the center of the area swept by the blades, $r$, can be determined. In addition,

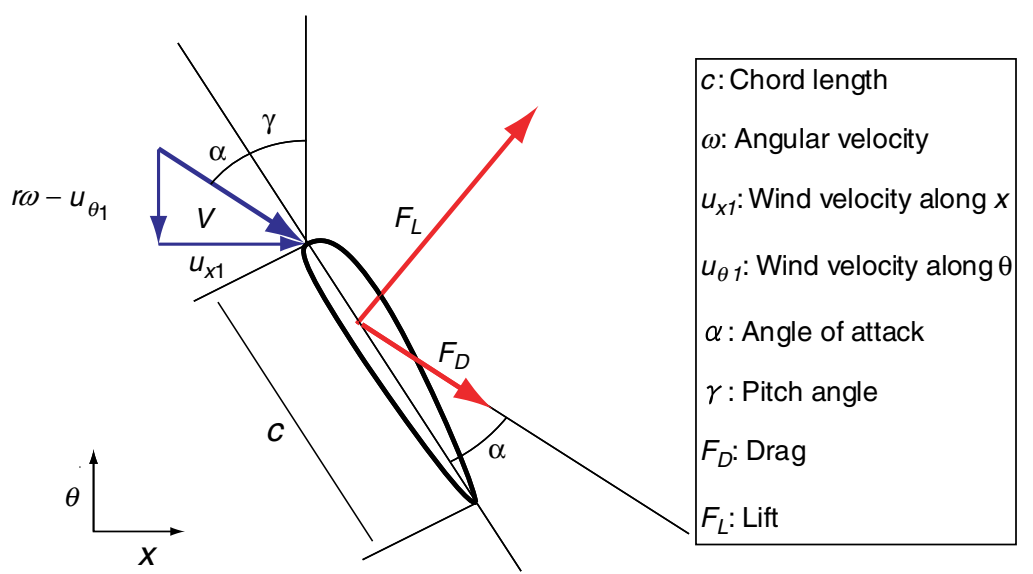

Figure 8: Schematic of lift and drag acting on a blade element of a wind turbine. 
the angular velocity of the blades, $\omega$, is given as a known quantity. Therefore, $V$ and $\alpha$ can be determined from only $r, u_{x}$, and $u_{\theta 1}$. With the calculated value of $V$, the aerodynamic forces exerted on a blade element, i.e., lift, $F_{L}$, and drag, $F_{D}$, can be evaluated as:

$$
\begin{aligned}
& d F_{L}=C_{L} \frac{1}{2} \rho V^{2} c d r \\
& d F_{D}=C_{D} \frac{1}{2} \rho V^{2} c d r
\end{aligned}
$$

where $C_{L}$ and $C_{D}$ represent the lift and drag coefficients, respectively and the values of these coefficients have previously been empirically determined (Fig. 9). The values of $C_{L}$ and $C_{D}$ can also be determined as a function of $r, \alpha$, and information on the blade configuration. Similarly, the chord length, $c$, is a function of $r$. A coordinate transformation is performed on the aerodynamic forces, which yields the $x$ - and $\theta$ - components of these forces, $F_{x}$ and $F_{\theta}$ as:

$$
\begin{aligned}
d F_{x} & =d F_{L} \cos (\alpha+\gamma)+d F_{D} \sin (\alpha+\gamma) \\
& =\left(C_{L} \cos (\alpha+\gamma)+C_{D} \sin (\alpha+\gamma)\right) \frac{1}{2} \rho V^{2} c d r
\end{aligned}
$$
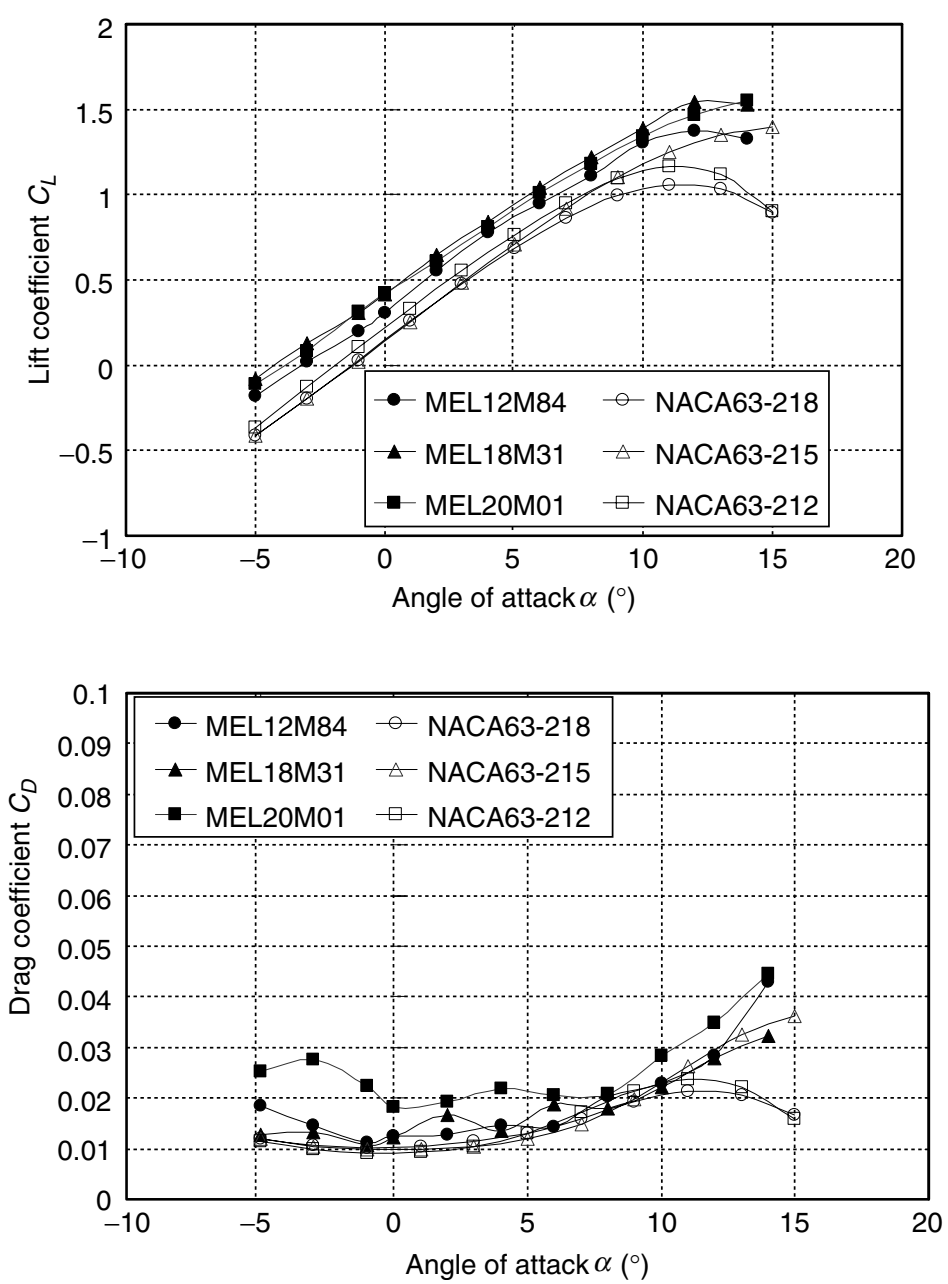

Figure 9: Lift and drag coefficients of the two blades. 


$$
\begin{aligned}
d F_{\theta} & =d F_{L} \sin (\alpha+\gamma)-d F_{D} \cos (\alpha+\gamma) \\
& =\left(C_{L} \sin (\alpha+\gamma)-C_{D} \sin (\alpha+\gamma)\right) \frac{1}{2} \rho V^{2} c d r
\end{aligned}
$$

Here, "the external forces exerted by the rotating blades on the fluid" is approximated as "the external forces exerted on the fluid within the disk-shaped volume with thicknes $\Delta L$ upon the passage of flow through the volume." If the $x$ - and $\theta$ - components of the corresponding external forces (body forces) are represented by $f_{x}$, and $f_{\theta}$ and action and reaction are taken into consideration, the following relationships hold:

$$
\begin{aligned}
& f_{x} 2 \pi r \Delta L d r=-Z d F_{x} \\
& f_{\theta} 2 \pi r \Delta L d r=-Z d F_{\theta}
\end{aligned}
$$

where $\mathrm{Z}$ is the number of blades on the turbine. From these relationships,

$$
\begin{aligned}
f_{x} & =\frac{-Z d F_{x}}{2 \pi r \Delta L d r} \\
& =-\left(C_{L} \cos (\alpha+\gamma)+C_{D} \sin (\alpha+\gamma)\right) \frac{Z c}{4 \pi r \Delta L} \rho V^{2} \\
f_{\theta} & =\frac{-Z d F_{\theta}}{2 \pi r \Delta L d r} \\
& =-\left(C_{L} \sin (\alpha+\gamma)-C_{D} \cos (\alpha+\gamma)\right) \frac{Z c}{4 \pi r \Delta L} \rho V^{2}
\end{aligned}
$$

can be derived. In order to model $f_{x}$, and $f_{\theta}$ as external forces exerted by the rotating blades, Equations (9) and (10) were included as external force terms in the Navier-Stokes Equation for the portion of the computational domain in which the turbine was located (refer to Fig. 3; in the present simulation, this portion of the computational domain extended over 5 gridpoints in the streamwise direction).

\section{NUMERICAL ANALYSIS OF AIRFLOW AROUND THE LONG-STYLE WIND LENS TURBINE}

\section{I. Validation of numerical analysis results against wind tunnel experimental data}

In order to validate the numerical simulation results, the wind velocity and static pressure inside the long-style diffuser shroud of the Wind Lens turbine were measured along a line in the streamwise $(x)$ direction at a radial position of $r=0.3 D$ in a wind tunnel experiment, and the experimental data are compared to the simulation results. Fig. 10 shows a schematic of the experimental arrangement.

First, the numerical and experimental data of the streamwise $(x)$ airflow velocity, $u_{x}$, (see Fig. 8) and static pressure are compared for the case with no wind turbine blades (Figs. 11 and 12). Although the values near the maximum of the airflow velocity and those near the minimum of the static pressure disagree slightly between the numerical and experimental results, the airflow velocity and static pressure are generally in good agreement.

Subsequently, the numerical and experimental data of the airflow velocity and static pressure are compared for the case with wind turbine blades (Figs. 13 and 14). The numerical and experimental static pressure data agree well with each other. As for the airflow velocity, the numerical and experimental data also agree well up to approximately $x / D=0.75$. 


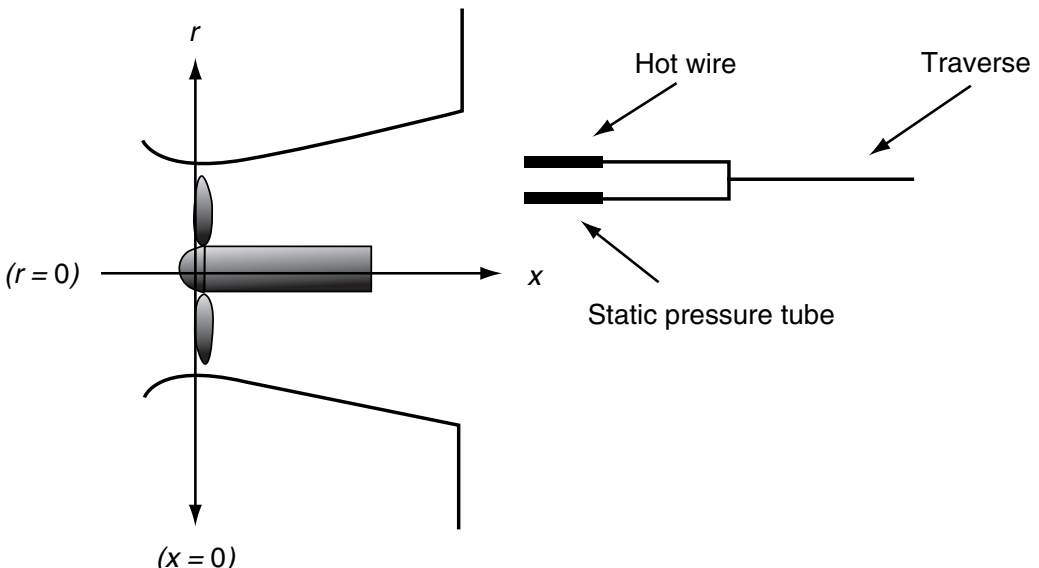

Figure 10: Experimental arrangement for velocity and pressure measurement.

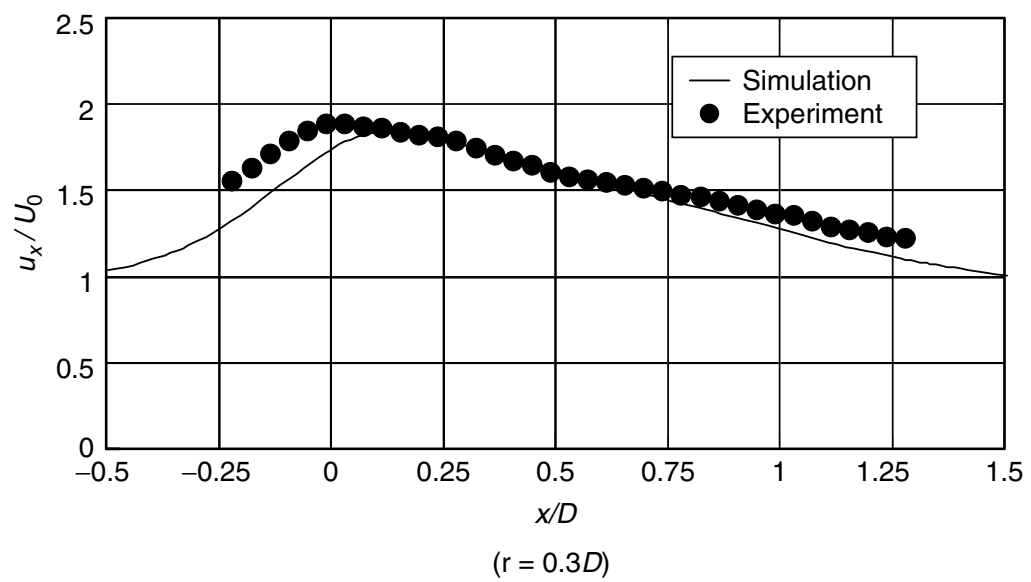

Figure 11: Distribution of the streamwise velocity, $u_{x}$, without wind turbine blades.

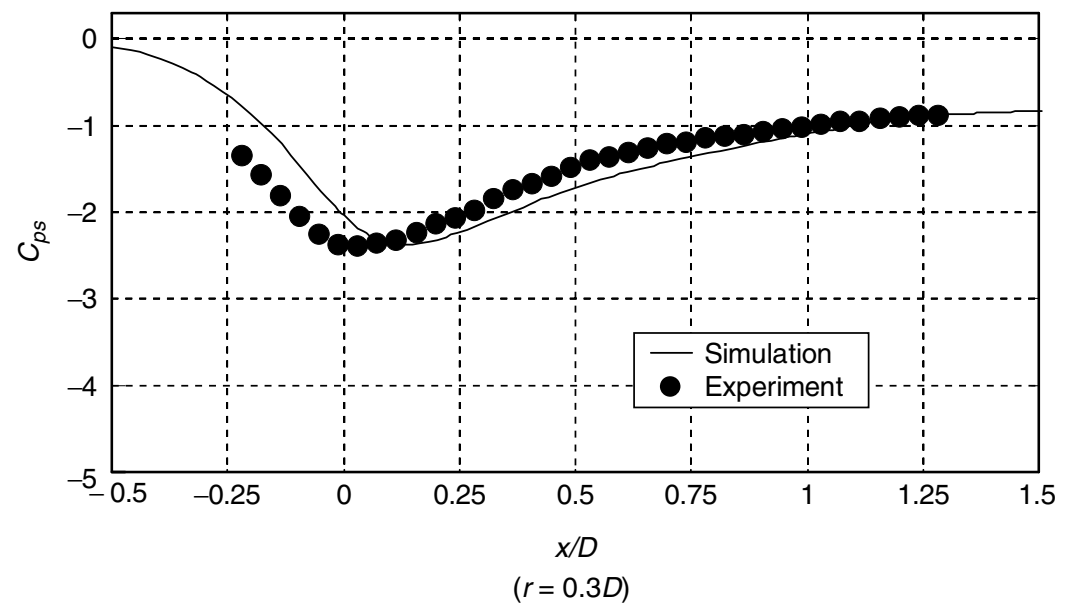

Figure 12: Distribution of the static pressure without wind turbine blades.

However, beyond this value of $x / D$, the disagreement between the numerical and experimental data becomes evident, which is likely attributable to highly turbulent conditions in the wake behind the wind turbine. 


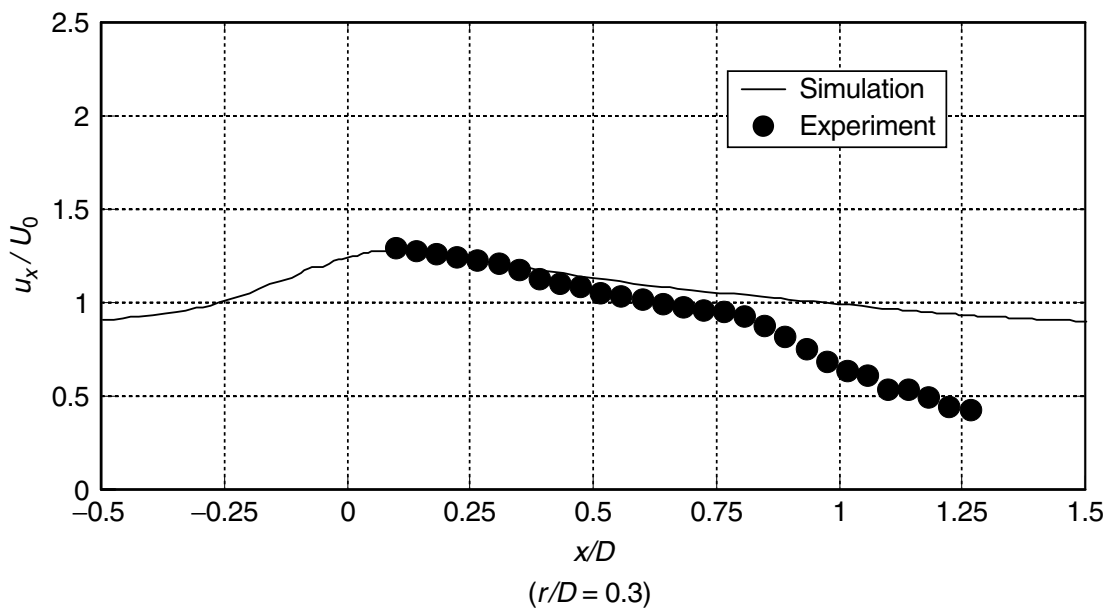

Figure 13: Distribution of the streamwise velocity, $u_{x}$, with wind turbine blades $(\lambda=4.5)$.

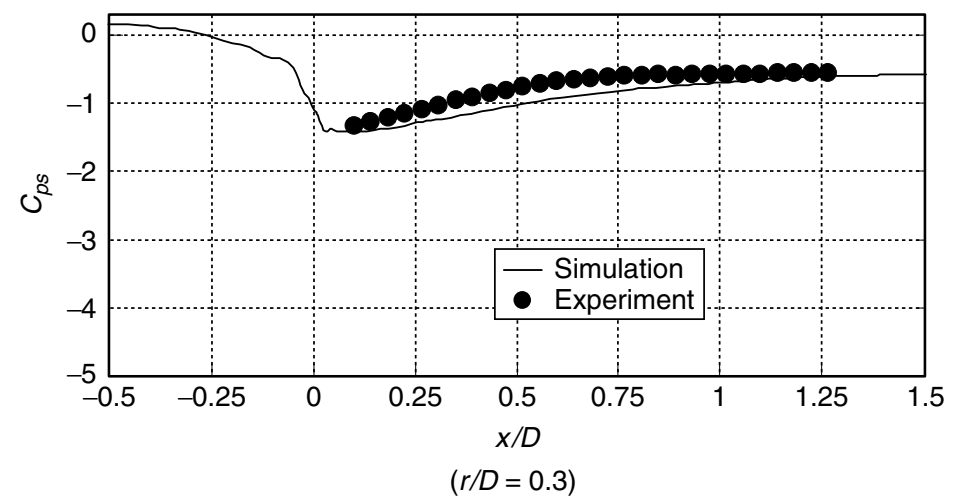

Figure 14: Distribution of the static pressure with wind turbine blades $(\lambda=4.5)$.

\subsection{Instantaneous and time-averaged flow fields}

In order to investigate what types of effects are caused by the actuator-disk model of the wind turbine blades on the airflow field inside and around the flanged-diffuser shroud, the instantaneous flow fields obtained from the numerical simulation are compared between the cases with and without the wind turbine blades (Figs. 15 and 16). While large-scale flow separation occurs along the internal wall of the diffuser shroud for the case without wind turbine blades, no flow separation occurs along the internal wall of the diffuser shroud for the case with wind turbine blades $(\lambda=4.5)$. In other words, the presence of the rotating wind turbine blades suppresses flow separation along the internal wall of the diffuser shroud. In the actuator-disk model of the wind turbine blades, drag and rotational forces exerted on the flow are given by Equations 9 and 10, respectively. Accordingly, the suppression of the flow separation may be explained by the following causes: 1) as a result of the wind turbine blades having become a resistance to the flow, the fluid moves toward the tip clearance space between the diffuser shroud wall and the blade tips, i.e., the locations at which the loading of the turbine blades is small, or 2) the rotational forces exerted by the actuator-disk model of the wind turbine blades direct the flow toward the internal wall of the diffuser shroud, and the flow moves along the internal wall of the diffuser shroud.

In order to examine the rotational force exerted by the actuator-disk model of the wind turbine blades, Fig. 17 shows the time-averaged streamlines in $r-\theta$ coordinate viewed from 


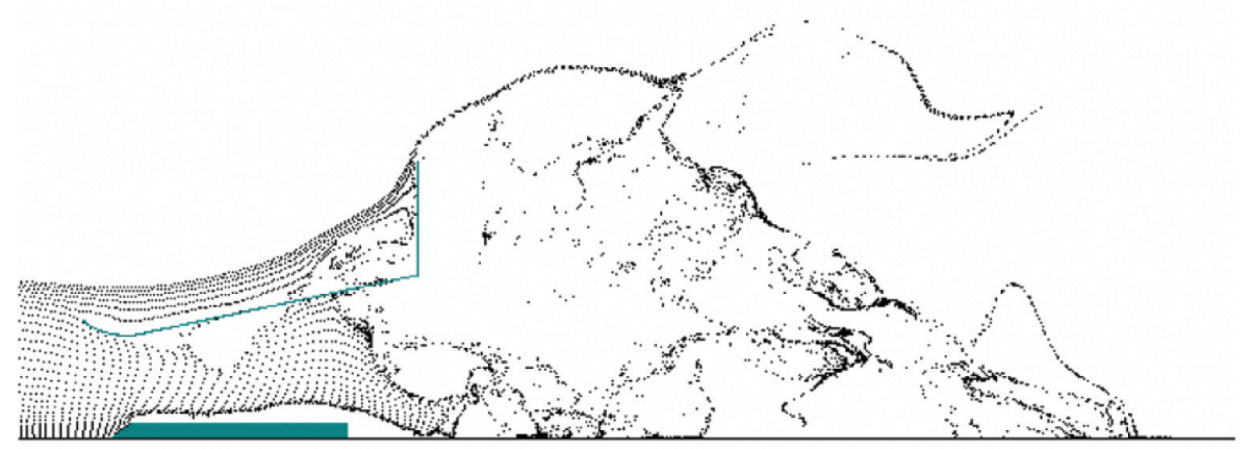

Figure 15: Instantaneous flow field for the simulation without wind turbine blades.

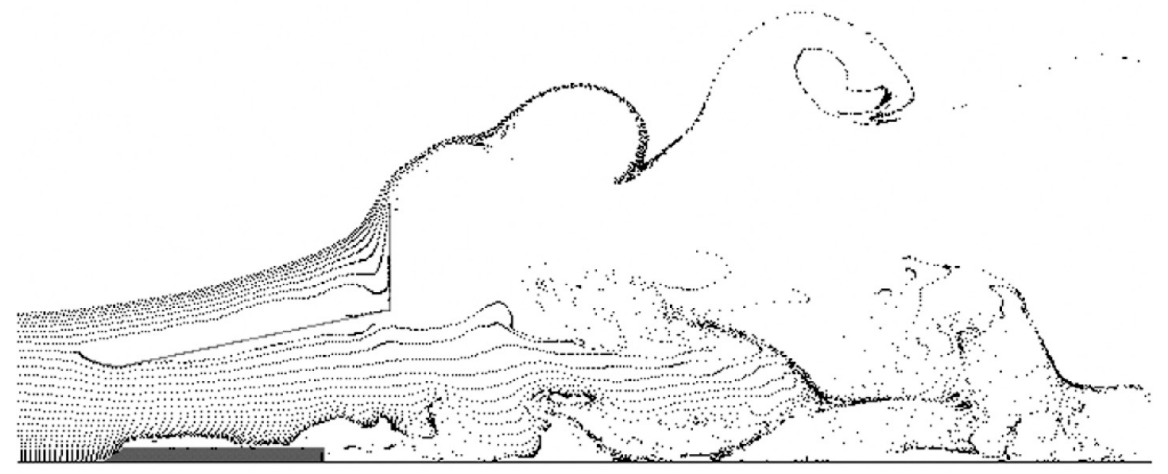

Figure 16: Instantaneous flow field for the simulation with wind turbine blades $(\lambda=4.5)$.

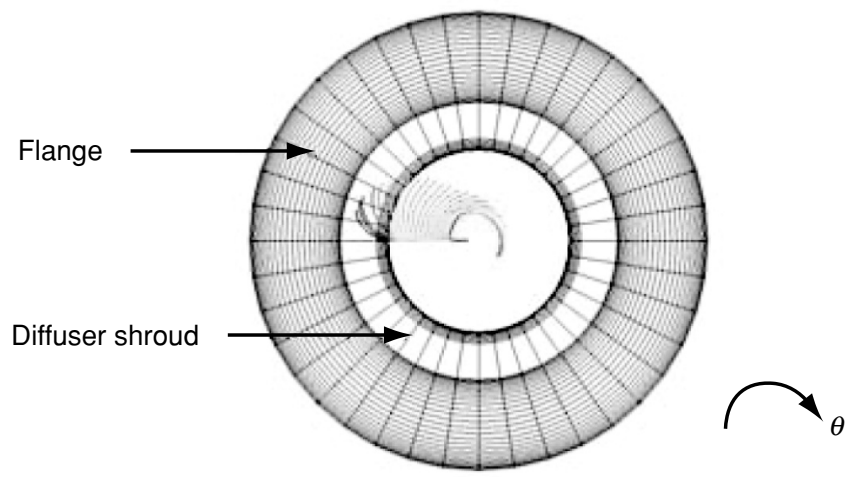

Figure 17: Time-averaged streamline in $r$ - $\theta$ coordinates for the simulation with wind turbine blades $(\lambda=4.5)$.

downstream of the outlet of the diffuser shroud. This figure illustrates that the fluid rotates in the $\theta$ - direction, and this motion occurs at higher speeds at the center of the diffuser shroud than near the diffuser shroud wall. At the same time, the flow near the diffuser shroud wall is directed in the $r$ - direction. These two results are in qualitative agreement with the finding of Abe et al. ${ }^{(4)}$ which made detailed measurements of flow velocities inside the diffuser shroud. 
Subsequently, the influences of the rotational force on the flow fields inside and outside the diffuser shroud are investigated. Figs. 18 and 19 show the three-dimensional time-averaged streamlines for the cases with and without the wind turbine blades, respectively. With no wind turbine blades, a symmetrical flow with a two-dimensional structure $(x-r$ plane $)$ emerges. In contrast, with rotating wind turbine blades, the flow becomes highly three-dimensional as in Fig. 19.

Fig. 20 shows the time-averaged streamlines in $x-r$ coordinate. The flow which moves along the internal wall of the diffuser shroud is apparent, and no large flow separation has formed. In addition, a large-scale separation vortex forms behind the flange, which creates a low pressure region near the outlet of the diffuser shroud.

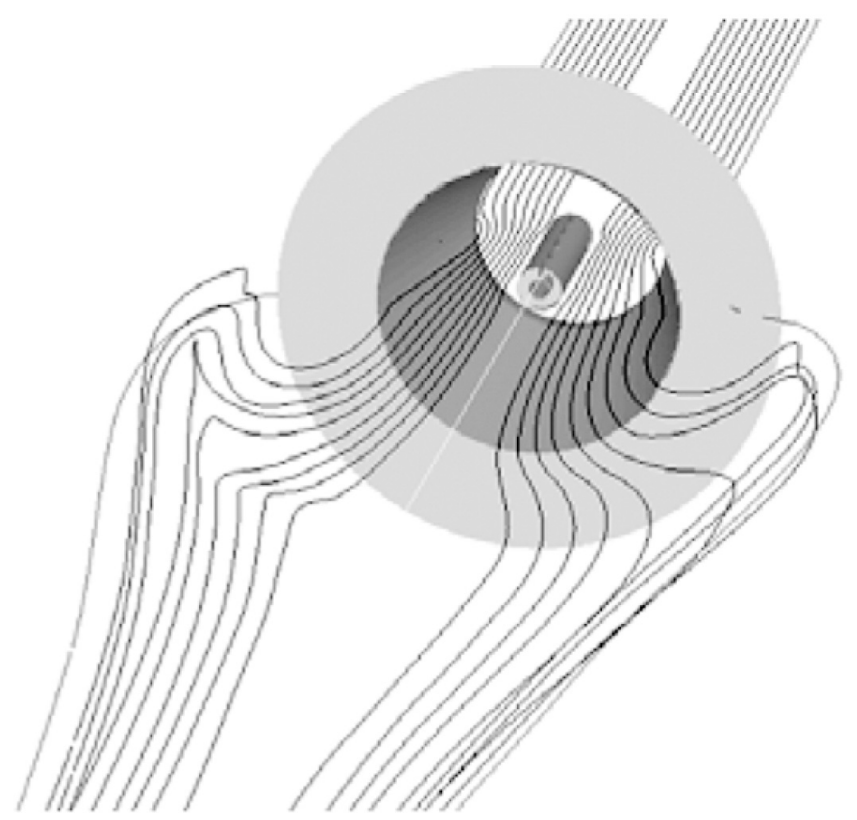

Figure 18: Time-averaged flow field for the simulation without wind turbine blades.

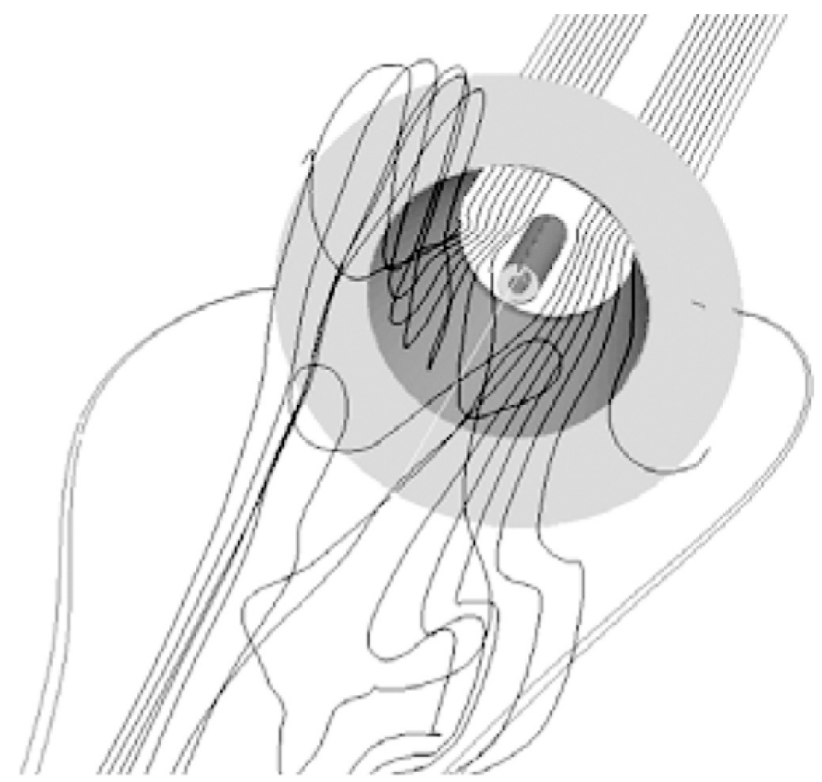

Figure 19: Time-averaged flow field for the simulation with wind turbine blades. 


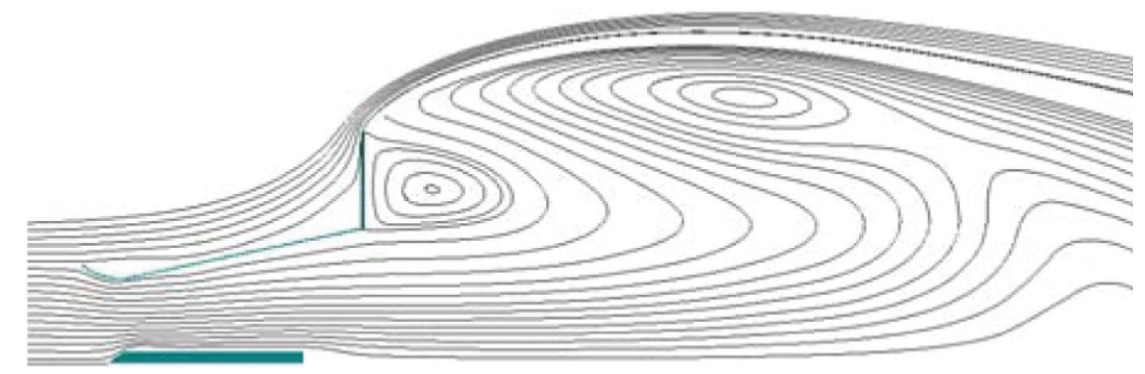

Figure 20: Time-averaged streamlines for the simulation with wind turbine blades $(\lambda=4.0)$.

\section{NUMERICAL SIMULATION OF AIRFLOW AROUND THE COMPACT-STYLE WIND LENS TURBINE}

\section{I. Validation of numerical simulation results against wind tunnel experimental results}

In the previous section, good agreement was found between the numerical simulation and experimental results for the airflow around the long-style Wind Lens turbine. ${ }^{(9)}$ For this section, a numerical simulation was performed on the airflow around a compact-style Wind Lens turbine with the actuator-disk approach. The diffuser shroud of a compact-style Wind Lens turbine is $15 \%$ of the length of that of a long-style Wind Lens turbine.

In order to validate the results of the numerical simulation for the compact-style Wind Lens turbine, the airflow velocity distributions within the diffuser shroud at the at radial positions $r$ were evaluated in a wind tunnel experiment, and these distributions are compared to those from the numerical simulation.

The measurements were made at three locations in the streamwise $(x)$ direction: $x / D=-0.127,0.0588$, and 0.122 , which correspond to the inlet, the throat, and the outlet of the diffuser shroud, respectively. Fig. 21 illustrates the comparisons between the simulated and experimental results. Although the airflow velocity distributions are in good agreement, the numerical simulation was unable to capture the increased airflow velocity near the blade tip in the throat of the diffuser shroud as measured in the wind tunnel experiment.

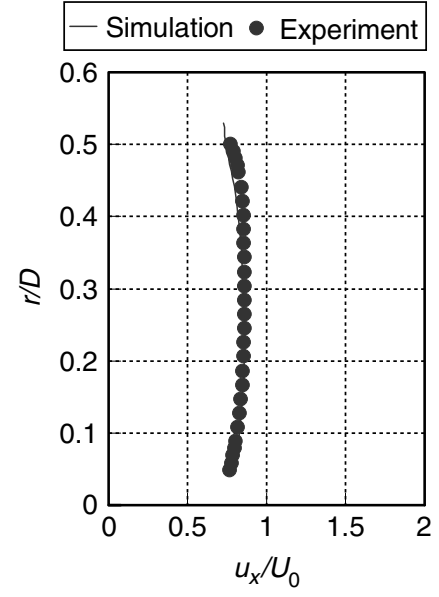

Inlet $(x / D=-0.127)$

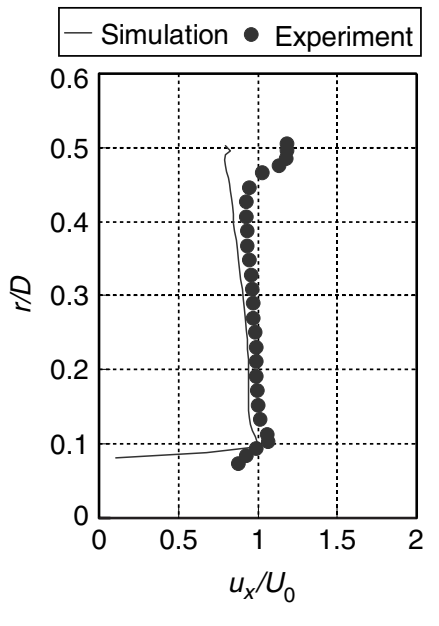

Throat $(x / D=0.0588)$

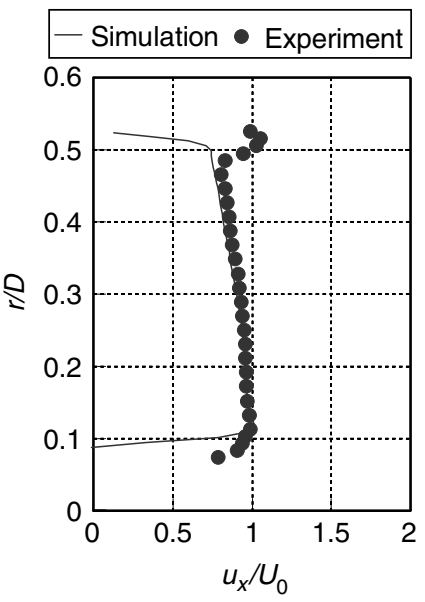

Outlet $(x / D=0.137)$

Figure 21: The streamwise velocity, $u_{x}$, for a wind turbine with a compact-style flanged-diffuser shroud. 


\subsection{Application of the tip-loss model}

The numerical simulation was unable to capture the increased airflow velocity near the blade tips in the throat of the diffuser shroud as observed in the wind tunnel experiment. Accordingly, the blade tip portion of the actuator-disk model was modified. Commonly, tip loss occurs on a turbine due to blade tip vortices, that is, blade loading decreases toward the blade tips. The measurements by Abe et al. ${ }^{(4)}$ showed that blade tip vortices are also generated on the Wind-Lens turbine. In order to include the effect of blade tip vortices, the external forces exerted by the rotating blades on the fluid which were modeled with the actuator-disk approach as in Equations 9 and 10 are now modified as:

$$
\begin{aligned}
& f_{x}=-F(r)\left(C_{L} \cos (\alpha+\gamma)+C_{D} \sin (\alpha+\gamma)\right) \frac{Z c}{4 \pi r \Delta L} \rho V^{2} \\
& f_{\theta}=-F(r)\left(C_{L} \sin (\alpha+\gamma)-C_{D} \cos (\alpha+\gamma)\right) \frac{Z c}{4 \pi r \Delta L} \rho V^{2}
\end{aligned}
$$

Here, $F(r)$ is defined as:

$$
F(r)=\left\{\begin{array}{cc}
1 & \left(r_{h} \leq r \leq 0.93 r_{t}\right) \\
\frac{1-0.7}{0.93 r_{t}-r_{t}}\left(r-0.93 r_{t}\right)+1 & \left(0.93 r_{t} \leq r \leq r_{t}\right)
\end{array}\right.
$$

This function will be referred to as the tip-loss function hereafter. Fig. 22 illustrates the values of the tip-loss function between the blade root, $r_{h}$, and blade tip, $r_{t}$.

With the modified model (Equations 11 and 12), airflow around the compact-style diffuser shroud was numerically simulated. Fig. 23 shows the profile of the airflow velocity within the throat of the diffuser shroud. The modified model is successful at qualitatively simulating the increased airflow velocity near the blade tips as observed in the wind tunnel experiment. Because the exact tip-loss function, $F(r)$, is unknown for the blades which were used in the present wind tunnel experiment, it was assumed that tip loss occurs along the final $7 \%$ of the blade at the blade tip, and the tip-loss function was set accordingly. The simulation results reveal that increased airflow velocity at the blade tip can be achieved by reducing blade tip loading. Because the tip-loss function, $F(r)$, can be arbitrarily set, a blade loading distribution which is well-suited for the Wind Lens turbine can be investigated by arbitrarily changing the blade loading distribution.

\subsection{Instantaneous and time-averaged flow field}

Figs. 24 and 25 illustrate the instantaneous flow fields with and without wind turbine blades, respectively. Without the blades, large flow separation occurs along the internal wall of the diffuser shroud. With the blades $(\lambda=4.0)$, no flow separation occurs along the internal wall of

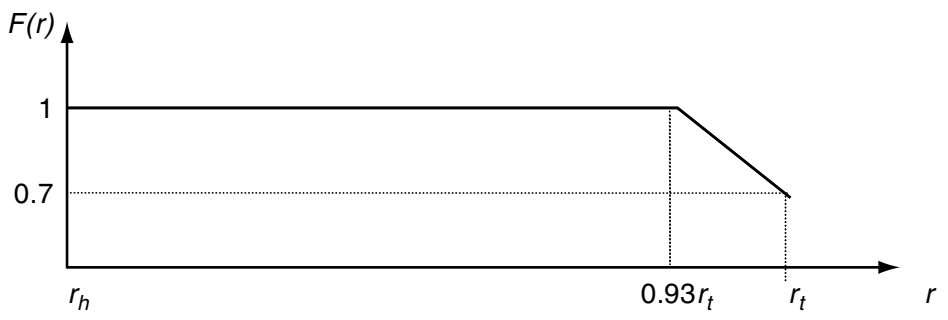

Figure 22: Distribution of tip-loss function $F(r)$. 


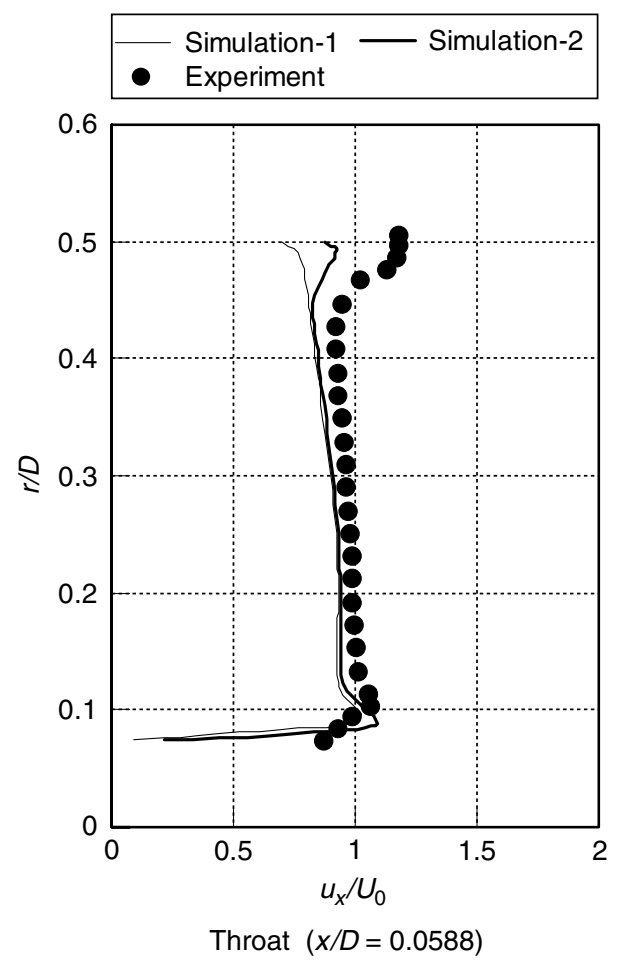

Figure 23: Distribution of the streamwise velocity, $u_{x}$ Simulation-1 (thin line): simulation results from the actuator-disk model alone (Section 4.1); Simulation-2 (heavy line); simulation results from the modified actuator-disk model which takes into account tip loss effects (Section 4.2).

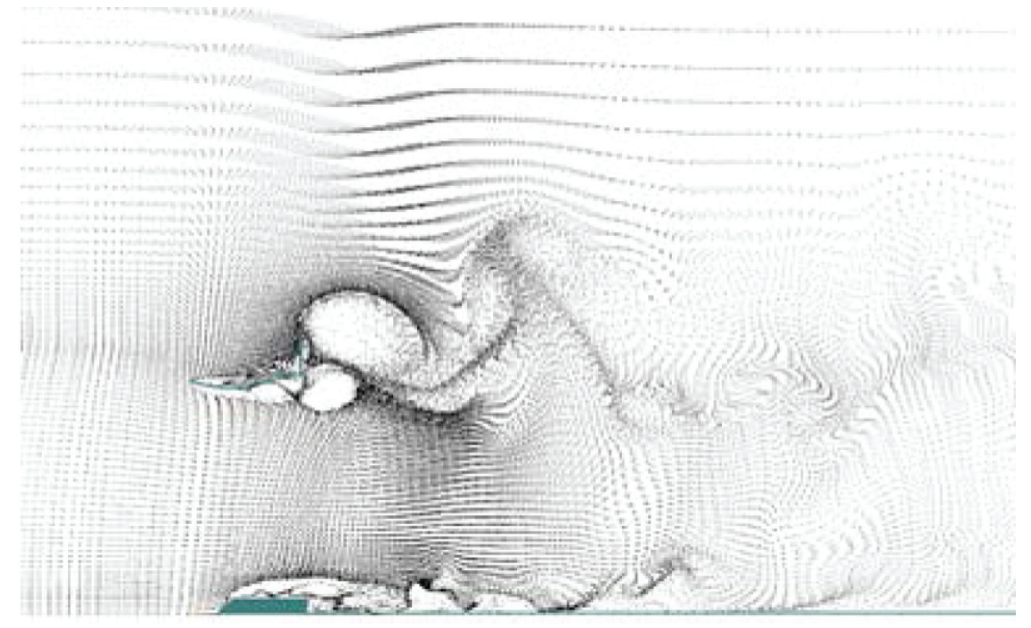

Figure 24: Instantaneous flow field for the simulation without wind turbine blades.

the diffuser shroud. These results are identical to those obtained for the long-style Wind Lens turbine. Therefore, the presence of the rotating wind turbine blades in the compact-style Wind Lens turbine also suppresses flow separation along the internal wall of the diffuser shroud.

Fig. 26 shows the time-averaged streamlines in $x$-r coordinate, which indicates formation of separated vortices behind the flange. These vortices generate negative pressure that is unique to the Wind-Lens turbine, and this negative pressure increases the wind velocity 


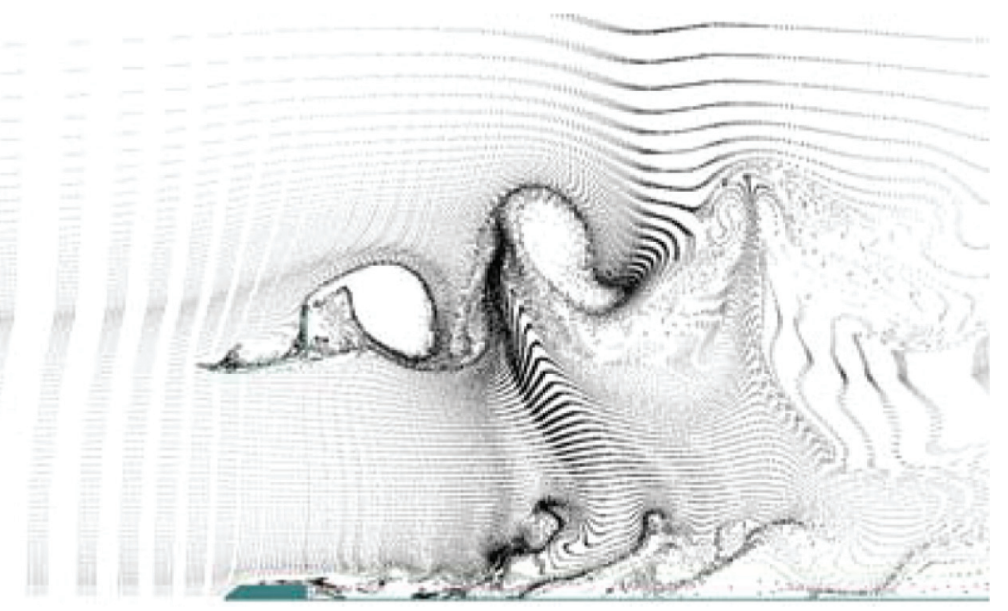

Figure 25: Instantaneous flow field for the simulation with wind turbine blades $(\lambda=4.0)$.

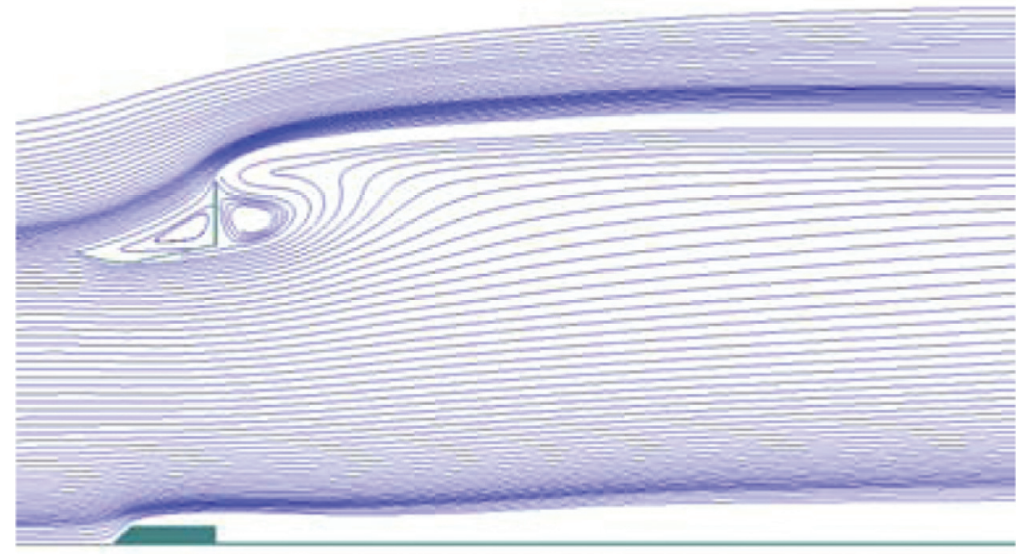

Figure 26: Time-averaged streamlines for the simulation with wind turbine blades $(\lambda=4.0)$.

particularly near the internal wall of the diffuser shroud. Thus, Fig. 26 implies that the compact-style Wind-Lens turbine is able to create a wind velocity enhancement effect similar to that of the long-style Wind-Lens turbine.

\subsection{Versatility of the numerical simulation for various types of blades}

The actuator-disk model of the wind turbine blades proposed in the present study can be applied to a numerical simulation of airflow around any blades as long as the lift and drag coefficients for the blade cross-sections and the blade configuration are known. In the present study, it was found that the results from the wind tunnel experiments and the numerical simulations agreed well for the airflow around the NACA and MEL blades, suggesting that the actuator-disk model of these blades is reliable. Ordinarily, the generation of complex grids and simulations of the blades as moving objects are necessary. However, the wind turbine models proposed in the present study are based on a simple technique, yet, enable highly accurate simulations of the distributions of the airflow velocity and static pressure in the vicinity of the blades. Although these models are unable to clarify details of the flow field such as the wakes generated behind the blades, the numerical models are highly capable in terms of wind turbine performance evaluations. 


\section{CONCLUSIONS}

With the use of rotating wind turbine blades modeled as actuator disks and the finite difference method, three-dimensional numerical simulations were performed for the airflow around Wind Lens turbines. The simulations led to the following findings:

- Comparisons against the results from wind tunnel experiments revealed that the numerical simulations based on the actuator-disk approach were effective for analyzing the airflow around the Wind-Lens turbines. Specifically, the simulated results of the streamwise $(x)$ distributions of the streamwise airflow velocity and the static pressure in the internal flow of the long-style Wind Lens turbine agreed well with the distributions of the same variables evaluated in the wind tunnel experiments. Furthermore, the numerical simulations were able to capture significant differences in the flow inside the diffuser shroud between the cases with and without wind turbine blades.

- By modeling the rotating blades as an actuator disk, the model was able to include the effect of the wind turbine as a resistance to the flow and the spiral flow downstream of the wind turbine. The former phenomenon suppressed flow separation downstream of the throat of the diffuser shroud due to the increased flow rate near the blade tips. Furthermore, the latter phenomenon generated threedimensional flow starting near the point at which the internal and external flows of the diffuser shroud met.

- The numerical simulations of the compact-style Wind Lens turbine modeled as an actuator disk could not capture the increase of flow rate near the blade tips. However, the addition of a tip-loss model to the actuator disk model led to a successful simulation of the flow-rate increase in the vicinity of the blade tips. The flow rate across the entire throat of the long-style Wind Lens turbine increased uniformly and significantly compared to the flow rate far upstream. In contrast, the flow rate increased mostly near the internal wall of the diffuser shroud in the throat of the compact-style Wind Lens turbine compared to the flow rate far upstream.

- The qualitative and quantitative agreement between the results from the wind tunnel experiments and the numerical simulations suggested that the proposed numerical simulation method is applicable for simulating the airflow around blades of arbitrary configuration. Because the forces exerted on the airflow by the blade elements are substituted as external force terms in the Navier-Stokes Equation with the actuator-disk approach, the actuator-disk model cannot capture detailed phenomena such as wake vortices shed from the blades. However, the actuator-disk model enables highly accurate simulations of the distributions of the airflow velocity and static pressure near the turbine blades, which allows reasonable evaluations of the wind turbine performance.

\section{REFERENCES}

Y. Ohya, T.Karasudani, A.Sakurai, Development of high-performance diffuser, J. Japan Soc. Aeronaut. Space Sci. 50 (2002), pp. 477-482 (in Japanese).

Y. Ohya, T.Karasudani, A.Sakurai, M.Inoue, Development of high-performance wind turbine with a brimmed-diffuser: Part2, J. Japan Soc. Aeronaut. Space Sci. 52 (2004), pp. 210-213 (in Japanese).

K. be, Y. Ohya, An investigation of flow fields around flanged diffusers using CFD, J. Wind Eng. Indust. Aerodyn.92 (2004) pp. 315-330. 
K. Abe, M. Nishida, A. Sakurai, Y. Ohya, H. Kihara, E. Wada, K. Sato, Experimental and numerical investigations of flow fields behind a small wind turbine with a flanged diffuser, J. Wind Eng. Indust. Aerodyn.93 (2005) pp. 951-970.

J.N. Sorensen, C.W.Kock, A model for unsteady rotor aerodynamics, J. Wind Eng. Indust. Aerodyn.58 (1995) pp. 259-275.

J.N. Sorensen, W.Z. Shen, Numerical Model of Wind Turbine Wakes, Trans. ASME, J.Fluids Eng.124 (2002) pp. 393-399.

M. Inoue, A. Sakurai, Y.Ohya, A simple theory of wind turbine with a brimmed diffuser, Turbomachinery 30 (2002) pp. 497-502(in japanese).

T. Matumiya, T. Kogaki, M. lida, K. Kieda, A development of high performance aerofoil, Turbomachinery 29 (2001) pp. 519-524.

H. Kume, Y. Ohya, T. Karasudani, K. Watanabe, Design of a shrouded wind turbine with brimmed diffuser using CFD, Proceedings of the Annual Conference of JSASS, The West Side Division, 2003, pp. 51-54(in Japanese). 